\title{
ДИССОЦИАТИВНАЯ ИОНИЗАЦИЯ НОРМАЛЬНЫХ НОНЕНОВ ПРИ РАЗЛИЧНЫХ ЭНЕРГИЯХ ИОНИЗИРУЮЩИХ ЭЛЕКТРОНОВ
}

Silvia RANG, M. MOORISEPP, O. EISEN. NORMAALSETE NONEENIDE DISSOTSIATIIVNE IONISATSIOON IONISEERIVATE ELEKTRONIDE ENERGIA MITMESUGUSTE VĀARTUSTE PUHUL

Silvia RANG, M. MOORISEPP, O. EISEN. DISSOCIATIVE IONIZATION OF NORMAL NONENES UNDER ELECTRON IMPACT AT VARIOUS ENERGIES OF BOMBARDING ELECTRONS

Ранее нами исследованы масс-спектры н-ноненов при 50 эв [']. В настоящей работе с целью выявить влияние энергии ионизирующих электронов $\left(E_{e}\right)$ на диссоциативную ионизацию и обнаружить условия, соответствующие наибольшим различиям в масс-спектрах изомеров, эти же соединения изучены в диапазоне $E_{e} 10-50$ эв. Масс-спектры снимались на масс-спектрометре MX-1303 при температуре системы напуска и ионного источника $200^{\circ} \mathrm{C}$, токе эмиссии электронов 0,75 ма и ускоряющем напряжении 2,2 кв. Интенсивности основных линий в масс-спектрах $H$-ноненов при 50,20 и 14 эв приведены в таблице. Выясняется, что устойчивость молекулы к электронному удару $\left(W_{M}\right) *$ возрастает в $5-7$ раз при перемещении двойной связи из положения 1 в положение 2. 2-, 3- и 4-Нонены имеют близкие значения $W_{M}$, что свидетельствует о бо́льшей степени стабилизации молекулярного иона за счет двух слабых электронодонорных групп у обоих концов двойной связи. Доля ионов, возникающих на основании известных механизмов распада $(\alpha-, \beta$ и $\gamma$-разрывы, $\beta$-разрыв с перегруппировкой водорода $\left.\left[{ }^{2,3}\right]\right)$, составляет $30-50 \%$ от суммарного ионного тока. Миграция двойной связи в молекулярных ионах приводит к качественно идентичным масс-спектрам изомеров, мало различающимся и по распределению интенсивностей пиков.

Распространенность характеристических ионов типа $\left(\mathrm{C}_{n} \mathrm{H}_{2 n-1}\right)^{+}$, $\left(\mathrm{C}_{n} \mathrm{H}_{2 n}\right)+$ и $\left(\mathrm{C}_{n} \mathrm{H}_{2 n+1}\right)+$ определяется положением двойной связи и энергией ионизирующих электронов (рисунок). При низких энергиях (ниже 18 эв) преобладают процессы, приводящие к образованию перегруппировочных ионов с $m / e 56,70$ и 84 , относительные количества которых снижаются по мере передвижения двойной связи к центру цепи. Одновременно происходит отрыв этильного и пропильного радикалов от молекулярного иона с возникновением ионов с $m / e 97$ и 83. По мере повышения $E_{e}$ общая распространенность перегруппировочных ионов типа $\left(\mathrm{C}_{n} \mathrm{H}_{2 n}\right)^{ \pm}(\Sigma 42)$ снижается, а ионов $\left(\mathrm{C}_{n} \mathrm{H}_{2 n-1}\right)^{+}(\Sigma 41)$ и $\left(\mathrm{C}_{n} \mathrm{H}_{2 n+1}\right)^{+}$ $(\Sigma 43)$ увеличивается и достигает максимального значения при $20-30$ эв. Суммарная интенсивность пиков ионов типа $\left(\mathrm{C}_{n} \mathrm{H}_{2 n-1}\right)^{+},\left(\mathrm{C}_{n} \mathrm{H}_{2 n}\right)^{ \pm}$.

* $W_{M}=\frac{I_{M}}{\Sigma I} \cdot 100$, где $I_{M}-$ интенсивность пика молекулярного иона, $\Sigma I-$ полный ионный ток. 


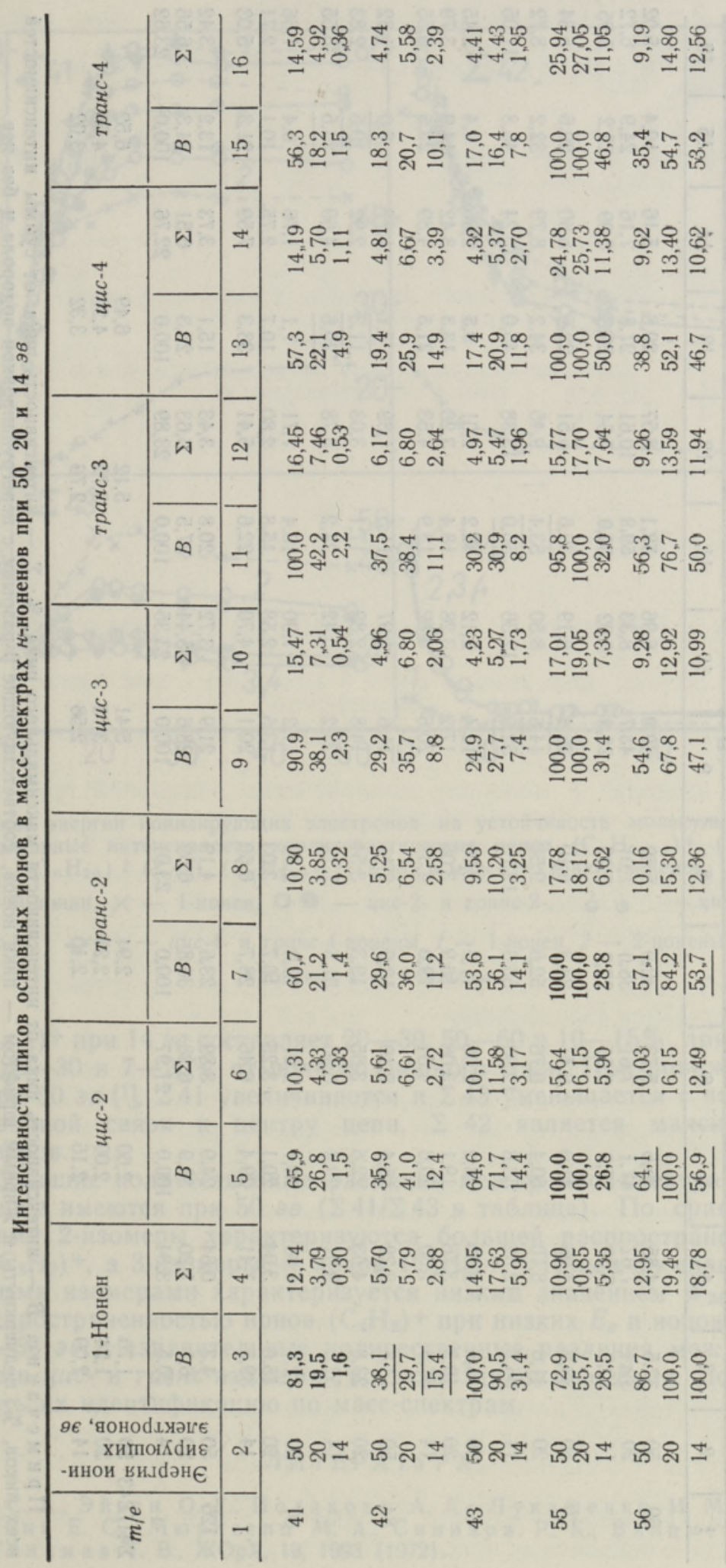




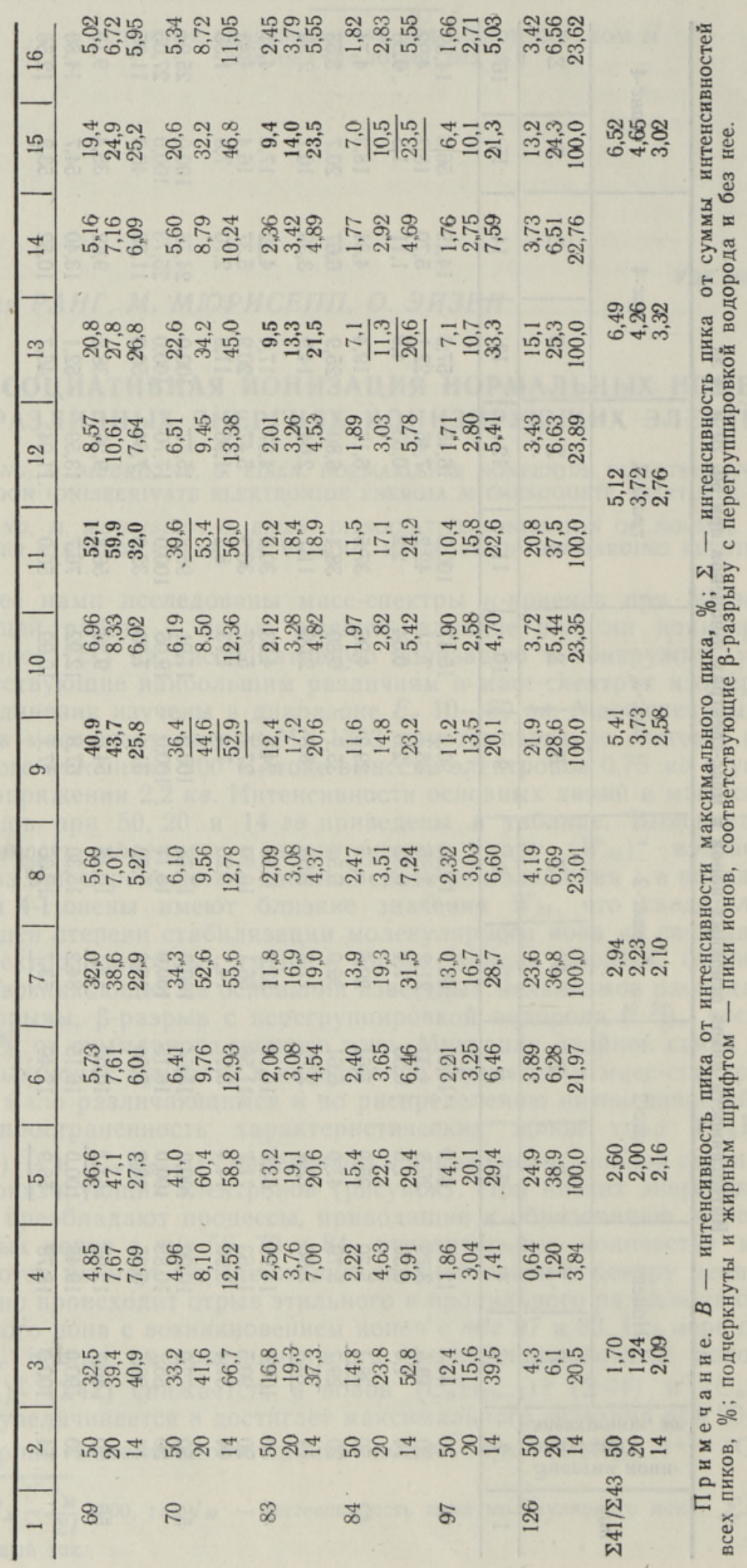




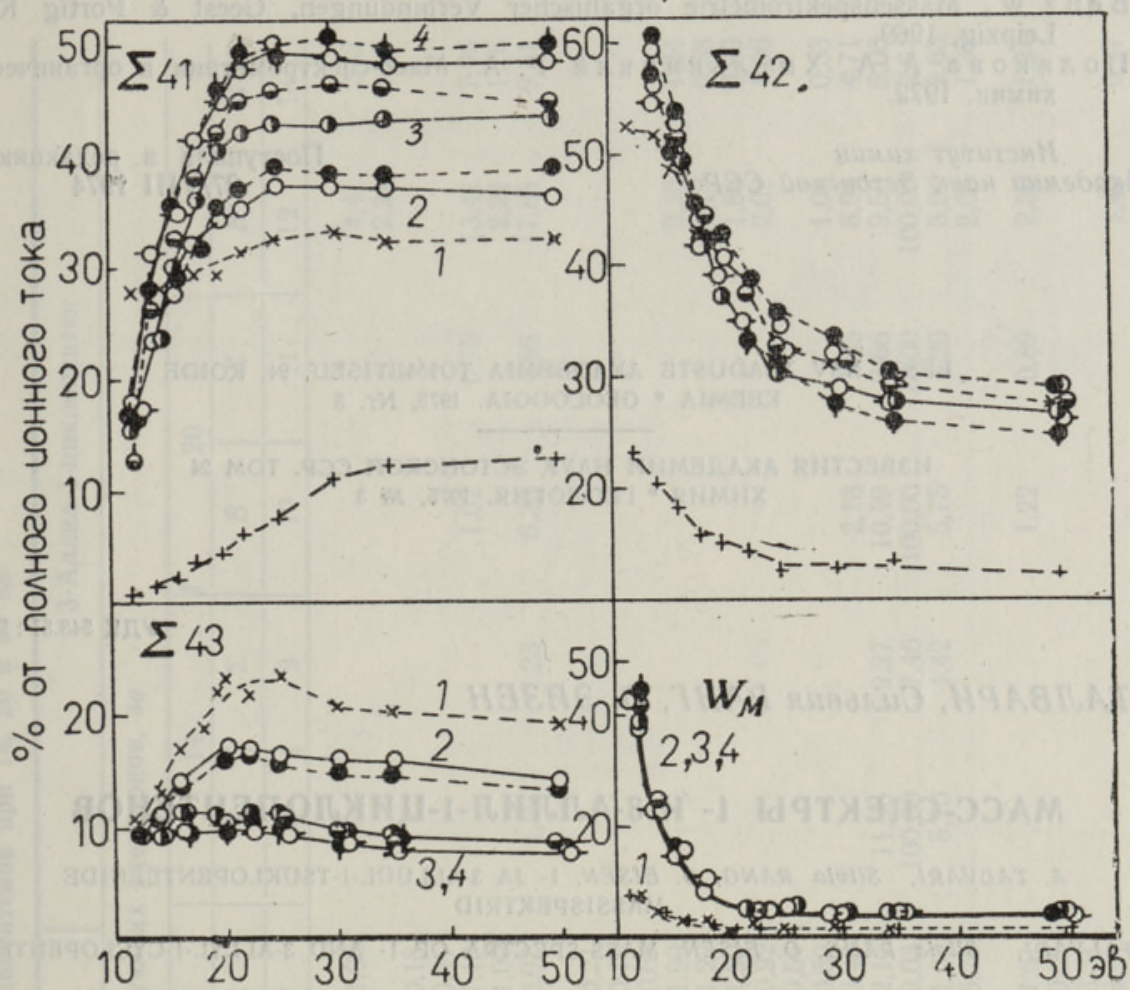

Влияние энергии ионизирующих электронов на устойчивость молекулы $W_{M}$ и суммарные интенсивности характеристических ионов $\left(\mathrm{C}_{n} \mathrm{H}_{2 n-1}\right)+(\Sigma 41)$, $\left(\mathrm{C}_{n} \mathrm{H}_{2 n}\right) \pm(\Sigma 42),\left(\mathrm{C}_{n} \mathrm{H}_{2 n+1}\right)+(\Sigma 43)$ в масс-спектрах $н$-ноненов.

+ - н-нонан, Х - 1-нонен, О транс-3-, о: - цис-4-и транс-4-нонены. 1 - 1-нонен, 2 - 2-нонены, 3 3-нонены, 4 - 4-нонены.

и $\left(\mathrm{C}_{n} \mathrm{H}_{2 n+1}\right)+$ при 14 эв составляет $20-30,50-60$ и $10-15 \%$, при 50 эв$30-50,25-30$ и $7-20 \%$ от полного ионного тока. При понижении $E_{e}$, как и при 50 эв [1], $\Sigma 41$ увеличивается и $\Sigma 43$ уменьшается с перемещением двойной связи к центру цепи, $\Sigma 42$ является максимальной у 2-изомеров.

Наибольшие количественные различия между масс-спектрами 2-, 3 и 4-ноненов имеются при 50 эв ( $\Sigma 41 / \Sigma 43$ в таблице). По сравнению с 4-ноненами 2-изомеры характеризуются большей распространенностью ионов $\left(\mathrm{C}_{3} \mathrm{H}_{7}\right)^{+}$, а 3 -изомеры - ионов $\left(\mathrm{C}_{3} \mathrm{H}_{5}\right)^{+}$. 1-Нонен по сравнению с остальными изомерами характеризуется низким значением $W_{M}$ и бо́льшей распространенностью ионов $\left(\mathrm{C}_{4} \mathrm{H}_{8}\right)+$ при низких $E_{e}$ и ионов $\left(\mathrm{C}_{3} \mathrm{H}_{7}\right)^{+}$ при 20-50 эв. Незначительные количественные различия между массспектрами цис- и транс-изомеров во всем диапазоне $E_{e}$ не позволяют проводить их идентификацию по масс-спектрам.

\section{Л ИТ Е Р АТ У РА}

1. Р ан С. А., Эйзен О. Г., Полякова А. А., Лукашенко И. М., Брод ский Е. С., Мюрисепп М. А., Синия в в Р. К., Вялиметс М. Т., Т и и м а а Т. В., ЖОрХ, 10, 1993 (1972). 